\title{
Ossified Subdural Chronic Hematoma: Two Cases Report and Literature Review
}

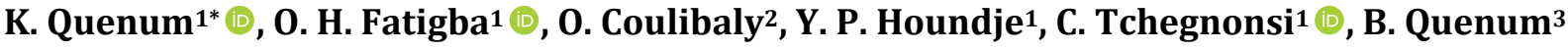 \\ ${ }^{1}$ Neurosurgery Department of University Hospital, University of Parakou, Parakou, Benin \\ ${ }^{2}$ Universite des Sciences, des Techniques et Technologiques de Bamako (usttb)/Hopital du Mali, Bamako, Mali \\ ${ }^{3}$ University of Abomey Calavi/CPMI-MFED, Cotonou, Benin \\ Email: ^kisitoq@gmail.com
}

How to cite this paper: Quenum, K. Fatigba, O.H., Coulibaly, O., Houndje, Y.P., Tchegnonsi, C. and Quenum, B. (2021) Ossified Subdural Chronic Hematoma: Two Cases Report and Literature Review. Open Journal of Modern Neurosurgery, 11, 29-33.

https://doi.org/10.4236/ojmn.2021.111004

Received: October 31, 2020

Accepted: December 22, 2020

Published: December 25, 2020

Copyright $\odot 2021$ by author(s) and Scientific Research Publishing Inc. This work is licensed under the Creative Commons Attribution International License (CC BY 4.0).

http://creativecommons.org/licenses/by/4.0/

\begin{abstract}
Ossified subdural chronic hematoma $(\mathrm{OSCH})$ is a rare disease that accounts $0.3 \%$ to $2 \%$ of subdural chronic hematoma which is common. The surgical management depends on his clinical expression. The aim of this study is to highlight the surgical procedure because the management of this type of lesion has no consensus. The authors reported two cases of $\mathrm{OSCH}$ which were successfully excised with good outcomes. Taking care during the procedure of dissection from parenchyma is the key for this surgery.
\end{abstract}

\section{Keywords}

Ossified Subdural Chronic Hematoma, Calcified Subdural Chronic Hematoma, Chronic Hematoma, Surgical Treatment

\section{Introduction}

Accounts from $0.3 \%$ to $2 \%$ of all chronic subdural hematoma ossified subdural chronic hematoma (OSCH) are a very rare disease [1] [2]. Ossified chronic subdural hematoma is different for calcified subdural chronic hematoma. It is radiological finding. The clinical features of $\mathrm{OSCH}$ are different and mimic a brain tumor with headache, weakness, numbness, seizures, memory impairment and complete deficit [2] [3] [4]. All the cases of OSCH should be treated surgically. We report two cases of patients who suffered from $\mathrm{OSCH}$ with a good outcome after the surgery procedure.

\section{Case 1}

A 13-year-old male patient was admitted for headache, vomited, seizures with left hemiplegia. The past history noticed a head trauma when he was 3-year-old 
with loss of conscience and hemi paresis. No brain computed tomography (CT) was performed at that time. Upon his admission, the Glasgow coma scale (GCS) was $9 / 15$ and his pupil reflex was normal. The laboratory test results were normal. A brain CT scan showed hemispheric hyper dense ossified rim with a mixed density lesion inside (Figure 1(a)). A bone window CT (Figure 1 (b)) revealed that some of the skull near the lesion had become thinner. The patient underwent surgery because of his condition and we made a large fronto-temporo-parietal bone flat. We found a thin dura which permitted to create a new bone flat inside the new ossified lesion. When the lesion was opened, we found inside a brown substance that we later confirmed to be an old hematoma, using histopathology. Without causing any damage to the brain, excision was carefully made by cutting the new bone. The day after surgery, control CT was performed with no brain edema and no bleeding and totally removal of the OSCH (Figure 1(c)). A week later his preoperative symptoms and raised intracranial pressure had resolved and he recovered from his neurological deficit.

\section{Case 2}

A 17-year-old boy was admitted with 1-month history of progressive right hemi paresis, urinary incontinence and short term memory lack and right side amyotrophic (Figure 2(a)). He had head trauma at age of 5 and suddenly presents a headache, vomiting, tinnitus and seizures and aphasia. The neurological examination revealed right central third cranial nerve palsy and hemi paresis, with Babinsky sign positive and aphasia. The Glasgow coma scale was evaluated to 10/15. A brain CT scan was performed and showed a hyper dense mass with on bone window an ossified subdural chronic hematoma with mass effect (Figure 2(b)). The mass was removed by craniotomy and confirmed OSCH which was thickly ossified on its surface. The surgical strategy concerns inner surface of dura mater and the ossified layer which was thick and extended. We were able to drill the ossified layer above the inner membrane (Figures 2(c)-(e)). One week post operation, CT revealed that the hematoma had been totally resected and the brain did not expand (Figure 2(f)). Over one month later his preoperative motor symptoms, seizures and aphasia had resolved and he became capable of all activities of daily living.

\section{Discussion}

Chronic subdural hematoma is usually one of the complications of head trauma. The pathogenesis of Ossified subdural chronic hematoma (OSCH) is not completely clear [3] [4] [5]. Many authors reported that local metabolic, poor circulation and absorption in the subdural space could be the factors that caused calcification [1] [3] [6] [7]. However, the hemorrhage is thought to progress from hyalinization to calcification and it takes at least six months for calcification to develop. But the mechanism of ossification of subdural chronic hematoma still unclear. $\mathrm{OSCH}$ may be observed more frequently in children and young adult 


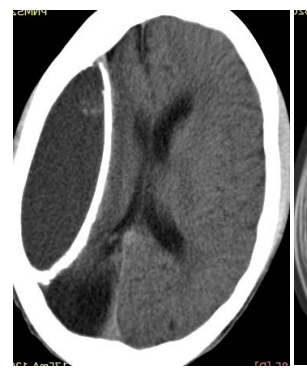

(a)

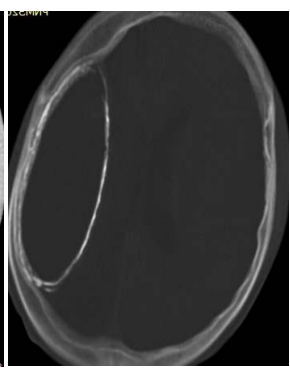

(b)

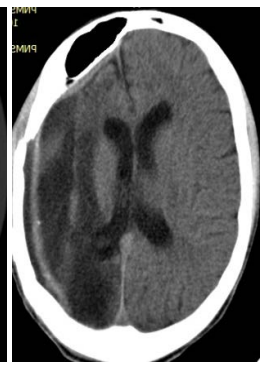

(c)

Figure 1. CT scan of the brain showing a large hemispheric mixed hyper dense lesion (a) and on bone window (b) an ossified rim which was totally removed (c).

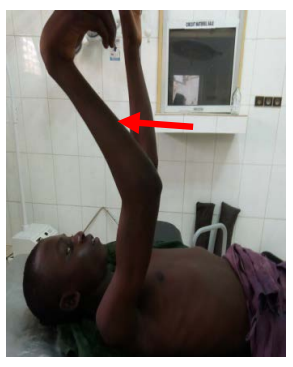

(a)

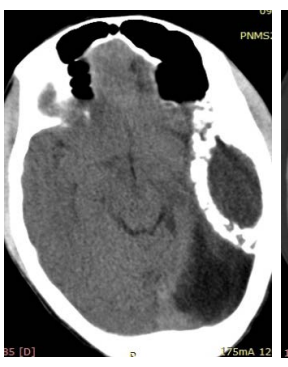

(b)

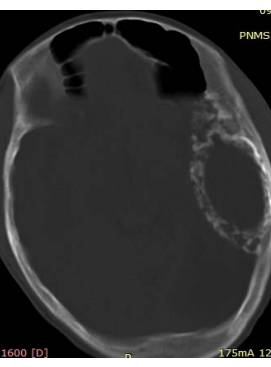

(b')

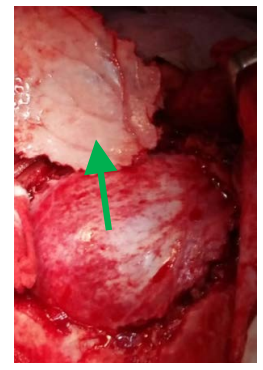

(c)

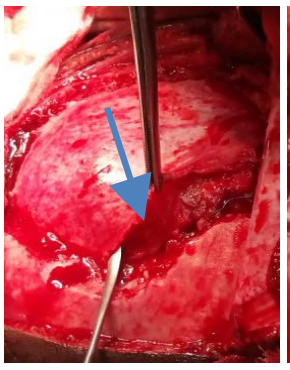

(d)

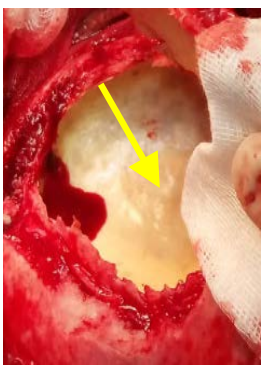

(e)

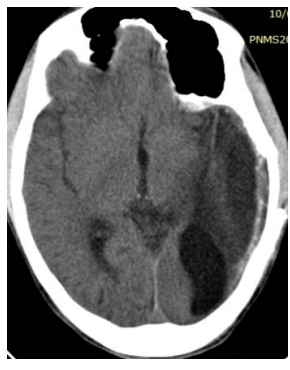

(f)

Figure 2. Clinical view of hemi amyotrophic right side (a); pre operative brain CT scan showing a temporo parietal hyper dense mass (b) with on bone window an ossified subdural chronic hematoma ( $\left.b^{\prime}\right)$. intra operative view showing craniotomy bone flap (c) (green arrow), dura thinner dura mater (d) (blue arrow) and ossified rim of OSCH (e) (yellow arrow). Post operative brain CT scan showing total removal of the mass.

than older people [8] [9]. In our cases, the patients lived for a long time with a neurological deficit after head trauma in childhood. The first (case 1) has past history about ten years head trauma with deficit and the second twelve years past history (case 2). The mechanism of ossification is quite longer than the calcification according to the cases reported.

The clinical features of $\mathrm{OSCH}$ and subdural chronic hematoma in these cases are similar to those non calcified or ossified [10] [11] [12]. The symptoms are acute headache deteriorisation of consciousness (case 1\&2). This symptomatology indicates that $\mathrm{OSCH}$ may have caused a chronic but mild increase in intracranial pressure that was high enough to cause neurological symptoms. Both of the patients were performed CT scan and the lesions appeared as $\mathrm{OSCH}$. The patients underwent surgery for total removal of the lesions as many authors 
recommended for symptomatic patients [7] [13]. In these cases, OSCH is diagnosed as mass effect, a surgical procedure should be considered because some $\mathrm{OSCH}$ can involve an active lesion that grows like a neoplasm. It has been suggested that the presence of brain atrophy may have been the reason why some cases are asymptomatic; which is not the case in case 2 . The CT scan showed an ischemic or cerebral infarction. Despite this the patient present twelve years after a symptoms and recovered totally after a radical removal.

\section{Conclusion}

Ossified Subdural Chronic Hematoma is a rare disease with a different clinical feature. The management is surgical when the symptoms are masse effect syndrom. Taking care during the procedure of the dissection from the parenchyma is the key for this surgery.

\section{Ethical Approval}

The study was approved by the Research Ethics committee of the affiliated Hospital of Parakou University.

\section{Informed Consent}

The patient's family had given their consent for the case reports to be published

\section{Conflicts of Interest}

The authors declare no conflicts of interest regarding the publication of this paper.

\section{References}

[1] Iplikcioglu, A.C., Akkas, O. and Sungur, R. (1991) Ossified Chronic Subdural Hematoma: Case Report. The Journal of Trauma, 31, 272-275. https://doi.org/10.1097/00005373-199131020-00023

[2] Turgut, M., Palaoglu, S. and Saglam, S. (1997) Huge Ossified Crust-Like Subdural Hematoma Covering the Hemisphere and Causing Acute Signs of Increasing Pressure. Child s Nervous System, 13, 415-417. https://doi.org/10.1007/s003810050111

[3] Moon, H.G., Shin, H.S., Kim, T.H., Hwang, Y.S. and Park, S.K. (2003) Ossified Chronic Subdural Hematoma. Yonsei Medical Journal, 44, 915-918. https://doi.org/10.3349/ymj.2003.44.5.915

[4] Xiao, Z.Y., Chen, X.J., Li, K.Z. and Zhang, Z.P. (2017) Calcified Chronic Subdural Hematoma: A Case Report and Literature Review. Transl Neurosci Clin, 3, 220-223. https://doi.org/10.18679/CN11-6030/R.2017.032

[5] Kaplan, M., Akgun, B. and Secer, H.I. (2008) Ossified Chronic Subdural Hematoma with Armored Brain. Turkish Neurosurgery, 18, 420-424.

[6] Aron-Echabe, E., Frieiro-Dantas, C. and Prieto-Gonzalez, A. (2014) Chronic Calcified Subdural Haematoma: Armoured Brain. Revue Neurologique, 58, 420-421. https://doi.org/10.33588/rn.5809.2014007

[7] Moon, K.S., Lee, J.K., Kim, T.S., et al. (2007) Controlateral Acute Subdural Hematoma Occurring after Removal of Calcified Chronic Subdural Hematoma. Journal of 
Clinical Neuroscience, 14, 283-286. https://doi.org/10.1016/j.jocn.2005.11.016

[8] Imaizumi, S., Onuma, T., Kameyama, M. and Naganuma, H. (2001) Organized Chronic Subdural Hematoma Requiring Craniotomy: Five Case Reports. Neurol Med Chir (Tokyo), 4, 19-24. https://doi.org/10.2176/nmc.41.19

[9] Per, H., Gumus, H., Tucer, B., Akgun, H., Kurtsoy, A. and Kumandas, S. (2006) Calcified Chronic Subdural Hematoma Mimicking Calvarial Mass: A Case Report. Brain and Development, 28, 607-609. https://doi.org/10.1016/j.braindev.2006.03.012

[10] Rao, Z.X., Li, J., Yin, H. and You, C. (2010) Huge Calcified Chronic Subdural Heamatoma. British Journal of Neurosurgery, 24, 722-723. https://doi.org/10.3109/02688697.2010.520763

[11] Sharma, R.R., Mahapatra, A., Pawar, S.J., Sousa, J. and Athale, S.D. (1999) Symptomatic Calcified Subdural Hematomas. Pediatric Neurosurgery, 31, 50-154. https://doi.org/10.1159/000028851

[12] Senapati, S.B., Kato, Y. and Rathore, L. (2019) A Successfully Excised into Loculated Calcified Chronic Subdural Hematoma: A Case Report. Indonesian Journal of Neurosurgery, 2, 38-41.

[13] Turgut, M., Akhaddar, A. and Turgut, A.T. (2020) Calcified or Ossified Chronic Subdural Hematoma: A Systematic Review of 114 Cases Reported during Last Century with a Demonstrative Case Report. World Neurosurgery, 134, 240-263. https://doi.org/10.1016/j.wneu.2019.10.153 